\title{
Regulating Artificial Intelligence through a human rights-based approach in Africa
}

\author{
Oyeniyi Abe, $\mathrm{PhD}$ \\ Lecturer in Law, Huddersfield Law School \\ University of Huddersfield, United Kingdom \\ (Research Associate, Centre for Comparative Law in Africa, Faculty of Law, University of Cape \\ Town, South Africa) \\ Corresponding author: o.o.abe@hud.ac.uk
}

And

Akinyi J. Eurallyah, LLM

$\mathrm{PhD}$ Candidate,

Schulich School of Law,

Dalhousie University,

Canada 


\title{
Regulating Artificial Intelligence through a human rights-based approach in Africa
}

\begin{abstract}
While the dawn of Artificial Intelligence (AI) solutions has aided in solving some of societal challenges, globalization and technological innovation potentially have the capability to disrupt, suspend or change existing legal order, preventing the realization of business and human rights principles. For example, with AI-enabled systems, Africans can now access better healthcare, education, health, and transportation. However, human rights violations induced by AI have the potential to undermine human rights concerns. This chapter contextualizes the usage of AI systems and its implications for human rights violations. With particular reference to Africa, it gives an overarching context capable of constructing legal reactions to corporate related human rights violations. Some of the questions posed and asked are: What are the ways human rights can be protected from exploitative tendencies of AI companies? How can African states, and businesses respond to regulatory challenges triggered by loss of work due to automation? What innovations and new methodologies are to be designed to engage with a sustainable and automated future? Finally, we propose reforms for corporate entities developing and deploying AI to respect human rights.
\end{abstract}




\title{
Regulating Artificial Intelligence through a human rights-based approach in Africa
}

Dr. Oyeniyi Abe*

Akinyi J. Eurallyah**

\begin{abstract}
While the dawn of Artificial Intelligence (AI) solutions have aided in solving some of societal challenges, globalization and technological innovation potentially have the capability to disrupt, suspend, or change existing legal order, preventing the realization of business and human rights principles. For example, with AI-enabled systems, Africans can now access better healthcare, education, health, and transportation. However, AI has the potential to undermine human rights concerns. This article contextualizes the usage of AI systems and its implications for human rights violations. With particular reference to Africa, it gives an overarching context capable of constructing legal reactions to corporate related human rights violations. Some of the questions posed are: What are the ways human rights can be protected from exploitative tendencies of AI companies? How can African states, and businesses respond to regulatory challenges triggered by loss of work due to automation? What innovations and new methodologies are to be designed to engage with a sustainable and automated future? Finally, we propose reforms for corporate entities developing and deploying AI to respect human rights.
\end{abstract}

Key words: Artificial Intelligence (AI), Africa, human rights accountability, privacy, data protection.

\section{Introduction}

The concept and concerns surrounding the impact of Artificial Intelligence (AI) on human rights within an African context has received few considerations in academic literature. ${ }^{1}$ The few literature appear to portray a disconnect between disruptive technologies broadly and human rights implications. ${ }^{2}$ On one hand, while state entities have deemed recourse to AI as a pathway to attracting investment within their territories, AI as a form of investment has been considered the next industrial revolution capable of fast tracking the growth and development of developing economies. $^{3}$ It is estimated that if properly implemented, AI has the potential to offer $\$ 15.7$

\footnotetext{
* Oyeniyi Abe is a Lecturer at the Law School, Huddersfield Business School, University of Huddersfield, United Kingdom. He can be reached at o.o.abe@hud.ac.uk. Special thanks to the anonymous reviewers.

** Akinyi Eurallyah is a PhD Candidate at the Schulich School of Law, Dalhousie University, Canada.

${ }^{1}$ M Romanoff and P Hidalgo-Sanchis, 'Building ethical AI approaches in the African context' (UN Global Pulse, 28 August 2019) <https://www.unglobalpulse.org/2019/08/ethical-ai-approaches-in-the-african-context/> accessed 26 June 2021; Clayton Besaw and John Filitz, 'Artificial Intelligence in Africa is a Double-edged Sword' (Science \& Technology: Governance, Technology, Urban Development, 16 January 2019) <https://ourworld.unu.edu/en/ai-inafrica-is-a-double-edged-sword> accessed 26 June 2021.

${ }^{2}$ M Risse, 'Human Rights and Artificial Intelligence: An urgently needed agenda' (2018) HKS Faculty Working Paper Series No. RWP18-015 <https://www.hks.harvard.edu/publications/human-rights-and-artificial-intelligenceurgently-needed-agenda> accessed 20 May 2021.
} 
trillion to the global economy by $2030 .{ }^{4}$ AI has also made work easier and faster compared to human intelligence. ${ }^{5}$ For instance, with the advent of autonomous vehicles, the transport industry is expected to record fewer road accidents and proper management of traffic-flows. ${ }^{6}$ Likewise, in the health sector, AI is making new diagnostic and decision-support tools for medical professionals. ${ }^{7}$ In addition, corporate entities have opted for intelligent personal assistants like Siri, Alexa, and Cortana that use voice recognition, thus making their businesses more efficient. ${ }^{8}$ AI has also been used in the creative industry to compose orchestral music, ${ }^{9}$ and generate short films. ${ }^{10}$

Unquestionably, AI is reshaping the economy, ${ }^{11}$ democratic participation, and society at large. One of the growing narratives in Africa is that AI cannot be regulated due to the technological innovation and disruptions they portend. Due to its relatively new phenomena, there are certain debates about the constitutionality or potential human rights implications around these technologies. These debates encompass the ways rightsholders interrelate with businesses, and in the process, modify business approaches towards fulfilling their responsibility to respect human rights. The question is how can manufacturing and usage of AI software be managed without social, ethical, and severe human rights implications? The disruption by AI has created concerns surrounding state and non-state actor's capability to use this tool as an instrument of oppression, which in many cases inexplicably affects the vulnerable members of the society. For instance, AI can lead to discrimination, loss of income, and uncertainties around the supply chain. This debate

${ }^{3} \mathrm{~T}$ Mills, 'The impact of artificial intelligence in the everyday lives of consumers' (Forbes, 7 March 2018) <https://www.forbes.com/sites/forbestechcouncil/2018/03/07/the-impact-of-artificial-intelligence-in-the-everydaylives-of-consumers/?sh=17fbd8f46f31> accessed 26 June 2021 .

${ }^{4}$ ibid.

${ }^{5} \mathrm{H}$ Wilson and P Daugherty, 'Collaborative Intelligence: Humans and AI Are Joining Forces' (Harvard Business Review, July-August 2018) <https://hbr.org/amp/2018/07/collaborative-intelligence-humans-and-ai-are-joiningforces> accessed 5 June 2020; J Anderson and L Rainie, 'Artificial Intelligence and the Future of Humans' (Pew Research Center, 10 December 2018) <https://www.pewresearch.org/internet/2018/12/10/artificial-intelligence-andthe-future-of-humans/> accessed 5 June 2020.

${ }^{6}$ P Stone, Rodney Brooks, and others, 'Artificial Intelligence and Life in 2030' Report of the 2016 Study Panel, <https://ai100.stanford.edu/sites/g/files/sbiybj9861/f/ai100report10032016fnl_singles.pdf> accessed 20 May 2021.

${ }^{7}$ ibid.

${ }^{8}$ ibid.

${ }^{9}$ R Moss, 'Creative AI: Computer composers are changing how music is made' (New Atlas, 26 January 2015) $<$ https://newatlas.com/creative-artificial-intelligence-computer-algorithmic-music/35764>accessed 19 April 2021.

${ }^{10}$ M Hutson, 'New algorithm can create movies from just a few snippets of text' (Science, 23 February 2018) <https://www.sciencemag.org/news/2018/02/new-algorithm-can-create-movies-just-few-snippets-text> accessed 25 June 2021.

11 D Wagner, 'How Artificial Intelligence is Changing the Global Economy' (Our World, 15 November 2018) $<$ https://ourworld.unu.edu/en/how-ai-is-changing-the-globaleconomy\#: :text=Artificial\%20intelligence $\% 20(\mathrm{AI}) \% 20$ and $\% 20$ machine,sectors $\% 20 \mathrm{of} \% 20$ the $\% 20 \mathrm{global} \% 20 \mathrm{econ}$ omy> accessed 25 June 2021. 
around human rights challenges 'power differentials and provides individuals, and the organizations that represent them, with the precise tools to question the motives of authoritative actors, such as states and businesses.' ${ }^{12}$ For example, the use of AI in algorithmic decisionmaking processes has introduced a new wave of challenges brought about by biased data and measurement error. ${ }^{13}$ These challenges greatly impact human rights. Further complicating this is the fact that victims do not have access to adequate remedies. A classic illustration is the utilisation of facial recognition software in surveillance cameras which has been used as mediums of discriminatory profiling, especially against certain races and mistaken identity of personalities. ${ }^{14}$ In addition, autonomous vehicles will not only lead to displacement of manual drivers but could also have adverse impacts on the environment. Businesses such as Cambridge Analytica have been accused of tampering with the voting systems of countries like Kenya leading to the question of whether the constitutionally guaranteed rights of Kenyan citizens may have been violated during the 2013 and 2017 presidential elections ? $^{15}$

A human rights-based approach within the context of this work is one which focuses on development of the people and protection of their fundamental human rights. AI must integrate a respect for human rights framework and ensure that fundamental liberties are integrated in regulatory frameworks, norms, standards, plans, and policies of government.

This article examines the potential of a human rights-based approach to AI in Africa. It explores various ways such adverse effects of AI on universally recognized human rights can be mitigated. Therefore, the questions this article seeks to answer are: how can we hold companies accountable for algorithm-based decisions? What are the ways human rights can be protected from exploitative tendencies of AI companies? How can African states, and businesses respond to regulatory challenges triggered by loss of work due to automation? What innovations and new methodologies are to be designed to engage with a sustainable and automated future? The article proceeds as follows: Part one is the introduction. Part two highlights the utilization of AI globally and the relevance of that utility to enhancing socio-economic development in Africa. It further examines the instrumentality of $\mathrm{AI}$ and its potential to violate human rights within the African context. Part three analyses the regional framework on AI in Africa, drawing lessons from other jurisdictions such as the European Union (EU) and the Organization of Economic Cooperation Development (OECD). This section further proposes an African Union governance regulatory framework for AI. Part four concludes the article.

\footnotetext{
${ }^{12} \mathrm{C}$ van Veen, 'Artificial Intelligence: What's Human Rights Got to do with It?' (Date and Society: Points, 14 May 2018) <https://points.datasociety.net/artificial-intelligence-whats-human-rights-got-to-do-with-it-4622ec1566d5> accessed 22 June 2021.

13 L Andersen, 'Human rights in the age of artificial intelligence' (Access Now, November 2018) <https://www.accessnow.org/cms/assets/uploads/2018/11/AI-and-Human-Rights.pdf> 24 June 2021.

14 Shai Gilboa, et. all, 'Faception is a Facial Personality Analytics Technology Company' (Faception) <https://www.faception.com> accessed 28 June 2021.

15 J Crabtree, 'Here's how Cambridge Analytica played a dominant role in Kenya's chaotic 2017 elections' (CNBC, 23 March 2018) <https://www.cnbc.com/2018/03/23/cambridge-analytica-and-its-role-in-kenya-2017-elections.html $>24$ June 2021.
} 


\section{The Concept of Artificial Intelligence and Implications for Human Rights Violations} While most of the conception about AI focuses on making machines intelligent, the role of humans in this process complicates the human rights impact of AI. ${ }^{16}$ Several scholars have envisioned AI as a mechanized procedure that possesses the basic functionality of humans. ${ }^{17}$

AI is grouped according to the utility of their functions. First, basic AI increases the performance of business analytics solutions and improves normalcy in the functioning of digital platforms. ${ }^{18}$ These digital platforms are commonly used in online matching, chatbots, and credit scoring such as in M-Shwari (Kenya) Tala (Kenya) M-Kajy (Madagascar), and ValU (Egypt). Second, advanced AI simulates human cognitive abilities like perception, vision, and spatial processing, enabling the analysis of unstructured data like texts, images, and audio data. ${ }^{19}$ This intelligence structure has been used in domains like social media, facial and speech recognition, and medical diagnoses. Examples include China's Yitu Technology on facial recognition, Infervision which provides medical diagnoses within and beyond China, and NIO which provides autonomous vehicle technology. ${ }^{20}$ Third, autonomous AI enhances the ability to interact with humans and learn on its own. ${ }^{21}$ Its prototypes include Fetch Robotics, Boston Dynamics, and Hanson Robotics.

Despite their daily interactions with AI systems, the public perception of AI in Africa is largely amorphous, and the impact of these systems on human rights protections have not been considered in literature. For example, public attitudes towards AI tend to be more pragmatic, measuring these systems based on the objective of end users, the importance of utilizing AI compared with other approaches, the inappropriateness of these technologies and how it violates privacy, and the extent of human involvement in decision-making.

\subsection{Opportunities and Solutions of AI for Socio-Economic Development in Africa}

While guaranteeing socio-economic rights, AI can drive growth and enhance development in Africa in several ways including intelligent automation of the workforce with its associated risk of job losses, augmenting both labour and physical capital, and enhancing innovation. ${ }^{22}$ Automation has the potential to improve business production, thus lowering costs of

\footnotetext{
${ }^{16} \mathrm{~N}$ Nilsson, The quest for Artificial Intelligence: A history of ideas and achievements (Cambridge University Press 2010).

17 D Strusani and GV Houngbonon, 'The role of Artificial Intelligence in supporting development in emerging markets' (2019) EMCompass Note 69 <https://www.ifc.org/wps/wcm/connect/32e54505-3bfb-4198-b939ele8847715f1/EMCompass-Note-69-Role-of-AI-in-EMs.pdf?MOD=AJPERES\&CVID=mNdPiNf $>\quad$ accessed 28 June 2021, 1-2; S Russell and P Norvig, ‘Artificial Intelligence: A modern approach' (3rd edn, Pearson 2010).

18 Strusani and Houngbonon (n 17).

19 ibid.

${ }^{20}$ ibid.

21 ibid 2.

22 University of Pretoria, 'Artificial Intelligence for Africa: An Opportunity for Growth, Development and Democratisation' (Access Partnership, 28 November 2018) <https://www.up.ac.za/media/shared/7/ZP_Files/ai-forafrica.zp165664.pdf> accessed 28 June 2021.
} 
production. ${ }^{23}$ This directly increases output and indirectly increases consumption. In Africa, AI has been used in different sectors through a variety of means which are discussed below.

\subsubsection{Access to healthcare}

In the health industry, the most critical concern is providing options for effective treatment. ${ }^{24} \mathrm{AI}-$ centric solutions can speed up diagnoses, improve public health policy, and assist in preparing for global pandemics. It also improves health care delivery by having advanced care analytics to help medical personnel identify potential challenges. ${ }^{25}$ Kenya has the 'Sophie Bot' that can easily be accessed by patients instead of visiting the hospital. The Sophie Bot relies on AI to process and respond to concerns relating to sexual and reproductive health. ${ }^{26}$ Kenya's Medical Supply Agency and IBM's Watson utilise AI to transform healthcare supply chains. ${ }^{27}$ In addition, South Africa's Numberboost used AI to come up with a solution aimed at addressing the United Nations' Sustainable Development Goal of improving access to healthcare. ${ }^{28}$ Nigeria's Apmis uses AI to allow medical practitioners and personnel to share and exchange data easily, transparently, and securely. ${ }^{29}$

\subsubsection{Access to public services}

Public service delivery is a major challenge for Africans seeking accurate and efficient service. The goal is to reduce bottlenecks and redundancy in the service industry. ${ }^{30}$ The low level of satisfaction has created distrust and apathy towards seeking public sector assistance in providing essential services. Recourse to AI has shown that unnecessary bureaucracy is curtailed, leading to reduced costs of administrative procedures and increased delivery of public services. For example, Kenya's eCitizen uses AI to offer citizens and residents services such as, application for a passport, searching for a title deed, and application for marriage or business certificates without having to physically visit a government office.

\subsubsection{Access to Food}

\footnotetext{
${ }^{23}$ Strusani and Houngbonon, (n 17), page 4.

${ }^{24}$ L Sallstrom, O Morris, and H Mehta, 'Artificial Intelligence in Africa's Healthcare: Ethical Considerations' (September 2019) ORF Issue Brief No. 312< https://www.orfonline.org/wpcontent/uploads/2019/09/ORF_Issue_Brief_312_AI-Health-Africa.pdf > accessed 28 June 2021.

${ }^{25}$ U Pretoria (n 22) page 10.
}

26 I Amukasa, 'Sophie Bot' (Sophie Bot, Patient Innovation, 3 June 2019) <https://patientinnovation.com/post/2071?language $=\mathrm{en}>$ accessed 28 June 2021 .

27 'Solving Africa's healthcare logistics problems with AI' (BizCommunity 2021) $<$ https://www.bizcommunity.com/PDF/PDF.aspx?1=196\&c=159\&ct=1\&ci=179698 > accessed 28 June 2021.

${ }^{28}$ U Pretoria (n 22) 19.

${ }^{29}$ Sallstrom, Morris, and Halak Mehta (n 24) 4.

${ }^{30}$ U Pretoria (n 22) 8. 
The right to food is not guaranteed under the African Charter on Human and Peoples' Rights. ${ }^{31}$ Considering that access to food is a legal and policy issue, the realization of this right has become the focus of states through agricultural policies and programmes that guarantee food security. ${ }^{32}$ These guarantees can be facilitated through adaptation of AI, that will not only ensure coherent government policies but see to the implementation of such food policies.

Agriculture is critical to the sustainable development of African countries. It has an accumulative human capital amounting to over $65 \%$ of the continent's labour force. ${ }^{33}$ As a result of the increase in trade and the growing population, the continent's food market is predicted to increase from USD300 billion to USD1 trillion by $2030 .{ }^{34}$ However, the growth of the food industry is inhibited by land expropriation, uncultivable soil, famine, and incipient pest resistance. ${ }^{35}$ Yet, utilisation of AI based technology can improve production and efficiency in the food value chain. In Kenya, FarmDrive uses mobile phones, data, and machine learning to offer farmers an alternative credit scoring platform, ${ }^{36}$ thus minimizing the USD 450 billion global agriculture financing gap that 'prevents financial institutions from lending to creditworthy smallholder farmers. ${ }^{37}$ Similarly, Vital Signs gathers and analyses pixels' value and colour from satellite imagery data to predict rainfall and drought patterns. ${ }^{38}$ This guarantees farmers' access to information needed to increase food productivity, guiding Africans toward sustainable food development and at the same time safeguarding nutritious and resilient livelihoods. Information and communication technology, through appropriate data is essential to ensuring food security in Africa. Vital Signs is able to synthesize data into significant insights for farmers and policy makers. ${ }^{39}$ Nigeria's Zenvus uses machine learning to enhance farm yields and profits by not only advising farmers on when, how, and what to farm but also detecting outbreaks of diseases and

${ }^{31}$ African Charter on Human and People's Rights, (Adopted 27 June 1981, entered into force 21 October 1986) (1982) 21 ILM 58 (African Charter),

32 C Dejil, A Djurfeldt, and M Jirström, 'Agricultural Policy in Sub- Saharan Africa and its relevance for Smallholder Farmers, Women and Youth' (AgriFoSe2030 Reports 2017-1) <https://pub.epsilon.slu.se/16878/1/deijl_c_et_al_200415.pdf> accessed 28 June 2021.

${ }^{33}$ U Pretoria (n 22) 9.

${ }^{34}$ The World Bank, 'Africa's food markets could create one trillion-dollar opportunity by 2030', (The World Bank, 4 March 3013) <https://www.worldbank.org/en/news/press-release/2013/03/04/africas-food-markets-could-createone-trillion-dollar-opportunity-2030> accessed 27 June 2021.

${ }^{35}$ ibid.

36 Crowd 360 'Alternative credit scoring for smallholder farmers' (FHI 360, 16 April 2018) $<$ https://crowd360.org/alternative-credit-scoring-

for-smallholder-farmers/ > accessed 28 June 2021.

${ }^{37}$ ibid.

38 Vital Signs, 'The Gold Standard of Environmental Monitoring Systems' (Vital Signs 2021) <http://www.vitalsigns.org/overview> accessed 28 June 2021.

39 ibid. 
40 'The Zenvus Advantage| Data-Driven Farming' (Zenvus, 2016) <https://www.zenvus.com> accessed 25 June 2021.

41 'Intelligent Tools for Perennial Crops' (Aerobotics, 2021) <https://www.aerobotics.com/?identifier=default-signup-button> accessed 25 June 2021.

42 B Ngugi, 'Kenyan banks among world's most profitable' Business Daily (Nairobi, 1 March 2018) <https://www.businessdailyafrica.com/bd/markets/market-news/kenyan-banks-among-world-s-most-profitable2192152> accessed 28 June 2021.

43 'Providing affordable financial services' (Kudi) <https://kudi.com> accessed 24 June 2021.

44 'M-PESA' <https://www.safaricom.co.ke/personal/m-pesa> accessed 24 June 2021.

45 'Mobile Loans in Kenya directly from your Smartphone' (TALA) <https://tala.co.ke> accessed 24 June 2021.

${ }^{46}$ U Pretoria (n 22) 13.

${ }^{47}$ U Pretoria (n 22) 14.

${ }^{48}$ Zenith Scan to Pay'<https://www.zenithbank.com/scan-to-pay///////> accessed 28 June 2021.

49 'ALAT by WEMA'<https://www.alat.ng> accessed 28 June 2021.

50 'Strider' <https://stridertech.co.za> accessed 28 June 2021. 
However, the extent to which these AI enabled systems impact human rights in Africa has not been critically considered. The next section discusses the challenges and impact of AI on human rights in Africa.

2.2 Challenges and Impact of AI on Human Rights

The implementation of AI-centric solutions in several sectors of the market economy results in a more reliable, accessible, and effective service. In this section, we investigate the instances where some of these human rights infringements do occur, noting that AI's ability to identify, categorize, and discriminate data amplifies the probability of human rights abuses. ${ }^{51}$

\subsubsection{Right to equality and non-discrimination}

By its nature, AI is tied to its ability to sort and filter data by ranking search results and classifying people into groups. ${ }^{52}$ In the process, AI treats different groups of people inversely. ${ }^{53}$ In certain instances, such difference in treatment results in positive consequences, especially when used in systems aimed at promoting diversity. ${ }^{54}$ However, in others, the use of AI solutions in sectors such as the criminal justice system have perpetuated injustice in judicial decision making such as sentencing, bail, and bond terms. ${ }^{55}$

The International Bill of Rights prohibit discrimination on any ground. ${ }^{56}$ The impact of such discrimination, especially on Africans, is twofold. ${ }^{57}$ First, discrimination by AI systems on an African generation may adversely impact on their health, economic opportunities, or wealth accumulation which consequently trickles down to the later generations. For example, AI solutions that prioritize factors like costs and profit over the wellbeing of the patient have the potential to recommend treatment based on the patient's insurance policy or ability to pay for the medical services, a fact which may result in denial of medical care. These systems, if employed on one generation, may incapacitate the ability of that generation to take care of its offspring. Secondly, AI solutions in the education sector that are racially biased can limit the admission of most Africans (blacks) in white-dominated academic institutions. Similarly, racial discrimination

\footnotetext{
${ }^{51}$ U Pretoria (n 22) 19.

${ }^{52}$ U Pretoria (n 22) 24.

53 ibid.

${ }^{54}$ ibid.

55 ibid.
}

56 The Universal Declaration of Human Rights (adopted 10 December 1948) UNGA Res 217 A(III) (UDHR); the International Covenant on Economic, Social, and Cultural Rights (adopted 16 December 1966, entered into force 3 January 1976) UNGA Res 2200A (XXI) (ICESCR); and the International Covenant on Civil and Political Rights (adopted 16 December 1966, entered into force 23 March 1976) 999 UNTS 171 (ICCPR) arts 26, 27; collectively referred to as the International Bill of Rights are the foremost human rights instruments drafted under the auspices of the United Nations.

${ }^{57}$ RM Blank, M Dabady, and CF Citro (eds), 'Measuring Racial Discrimination' (National Academies Press 2004). 
in the labour market in relation to hiring and performance appraisals could limit the wage growth and promotion of most Africans.

\subsubsection{Right to privacy and data protection}

Surveillance systems limits citizens' rights to privacy. ${ }^{58}$ Kenya's Vital Signs and South Africa's Aerobotics harvests data from satellite imagery. This technology can not only provide comprehensive data on an individual's movements but also predict their future location. ${ }^{59}$ The precision and invasive nature of these technologies can provide businesses operating in weak states the capability to stymie or impose constraints on human rights activists' actions and movements. ${ }^{60}$

Privacy is fundamental to human dignity ${ }^{61}$ and is recognized under international human rights law. ${ }^{62}$ These instruments safeguards citizens arbitrary or unlawful interference with anyone's privacy, family, home, correspondence, or reputation. ${ }^{63}$ The African Union Declaration of Principles on Freedom of Expression and Access to Information in Africa reinforces the people's right to privacy, including the confidentiality of their communications and protection of their personal information or data. ${ }^{64}$ Such protection is established by law in accordance with the principles of consent of the individual, fairness, autonomy in relation to their personal information, right to be notified of any unauthorised access to one's information, and protection from harmful sharing of the personal information such as non-consensual sharing of intimate images of women and child pornography. ${ }^{65}$ Equally, the Johannesburg Principles on National

\footnotetext{
${ }^{58}$ U Pretoria (n 22) 21.

59 ibid.

${ }^{60}$ S Zuboff, ‘The Age of Surveillance Capitalism’ (1st edn, PublicAffairs 2019).

${ }^{61} \mathrm{UDHR}$ art 12.
}

${ }^{62}$ Such international human rights law includes: International Convention on the Protection of the Rights of all Migrant Workers and Members of their Families (adopted 18 December 1990, entered into force 1 July 2003) Doc. A/RES/45/158, (ICPRMWMF) art 14; Convention on the Rights of the Child (adopted 20 November 1989, entered into force 2 September 1990) (CRC) art 16; European Convention for the Protection of Human Rights and Fundamental Freedoms (adopted 4 November 1950, entered into force 3 September 1953) Rome, 4.XI.1950 (ECPHRFF) art 8.

${ }^{63}$ See UDHR art 12; article 17 of ICCPR. See further, Charter of Fundamental Rights of the European Union, (adopted 7 December 2000, entered into force 1 December 2009) 2012/C 326/02 (CFR), art 7 confers upon everyone the right to respect his or her private and family life, home, and communications. With respect to data, Article 8 of CFR guarantees every European the right to have their personal data protected. Such data must be fairly processed for clearly stated objectives subject to the individual's consent or other legitimate basis founded on the law. The same proviso additionally allows everyone to access data which has been gathered concerning him or her, and an additional right to have such data rectified.

${ }^{64}$ See Declaration of Principles on Freedom of Expression and Access to Information in Africa, 2019 (Adopted by the African Commission on Human and Peoples' Rights at its 65th Ordinary Session held from 21 October to 10 November 2019) ACHPR/Res.350 (EXT.OS/XX) 2016, (DPFEAIA) art 97.

65 ibid art 100. 
Security, Freedom of Expression and Access to Information impose on States authoritative standards clarifying the legal scope of restrictions on freedom of expression on grounds of protecting national security, ${ }^{66}$ ensuring that they exercise proportionality ${ }^{67}$ in order to balance the achievement of the intended objective against the fundamental right to freedom of privacy and expression. $^{68}$

When not properly regulated, AI has the capability to mine and analyse big data sets which more often than not include personal data. The analysis of such data by AI systems may reveal individuals' sensitive personal information such as gender, sexual orientation, and marital status, thus warranting advanced levels of protection. ${ }^{69}$ Even though such international instruments protect citizens privacy rights, recognition by countries, citizens' rights to privacy, data protection and freedom of expression especially on social media have perennially been infringed upon by the complicity of businesses in cooperating with government to share data. For example, following Kenya's 2007 post-election violence that claimed the lives of thousands, there were efforts to monitor political conversations online as a broader effort to curb hate speech. ${ }^{70}$ The Kenyan government engaged the services of Cambridge Analytica to access and analyse the data of millions of Kenyans on Facebook, Twitter, and Google in a bid to determine and manipulate their political views on the incumbent presidency. ${ }^{71}$ This confirmed that online radicalization can be propagated by a deliberate strategy of violating peoples' online personal private data, misinformation, and manipulation by AI solutions in order to sway their political views in favour of an otherwise unpopular government.

\subsubsection{Right to work, and adequate standard of living}

The ICESCR mandates states to take steps to ensure everyone has the right to work. ${ }^{72}$ Such steps include technical and vocational guidance and training programmes; policies and techniques to

\footnotetext{
66 UNCHR 'Report of the Special Rapporteur, Mr. Abid Hussain pursuant to Commission on Human Rights resolution 1993/45 (1996). See Johannesburg Principles on National Security, Freedom of Expression and Access to Information (adopted 01 October 1995) U.N. Doc. E/CN.4/1996/39.

${ }^{67}$ Lingens v. Austria, 8 EHRR 407. Application Number 981/82, para 40 (1986).

${ }^{68}$ Johannesburg Principles (n 66) 3.

${ }^{69}$ U Pretoria (n 22) 20; See also S Levin, 'New AI can guess whether you're gay or straight from a photograph' (The Guardian, 7 September 2017) <https://www.theguardian.com/technology/2017/sep/07/new-artificial-intelligencecan-tell-whether-youre-gay-or-straight-from-a-photograph> accessed 28 June 2021; See also P Lewis, 'Facial recognition can tell if you're gay' (The Guardian, 7 July 2018) <https://www.theguardian.com/technology/2018/jul/07/artificial-intelligence-can-tell-your-sexuality-politicssurveillance-paul-lewis?CMP=Share_iOSApp_Other> accessed 28 June 2021.

${ }^{70}$ Nanjala Nyabola, 'Digital Democracy, Analogue Politics: How the Internet era is Transforming Politics in Kenya' (Zed Books 2018) 163.

71 ibid, 163.

${ }^{72}$ ICESCR (n 56) art 6.
} 
${ }^{73}$ ibid.

${ }^{74}$ ICESCR (n 56) art 11.

${ }^{75}$ See General Comment No. 18: The Right to Work (Art. 6 of the Covenant), UN Committee on Economic, Social and Cultural Rights (CESCR) E/C.12/GC/18.

${ }^{76} \mathrm{~K}$ Drum, 'You will lose your job to a robot - and sooner than you think", (MotherJones, November/December 2017) <https://www.motherjones.com/politics/2017/10/you-will-lose-your-job-to-a-robot-and-sooner-than-youthink/> accessed 25 June 2021; D Shewan, 'Robots will destroy our jobs - and we're not ready for it' (The Guardian,11 January 2017) <https://www.theguardian.com/technology/2017/jan/11/robots-jobs-employeesartificial-intelligence> accessed 25 June 2021.

${ }^{77}$ Shewan (n 76).

${ }^{78}$ ibid.

${ }^{79}$ D Meyer, 'Robots may steal as many as 800 million jobs in the next 13 years' (Fortune, 29 November 2017) $<$ https://fortune.com/2017/11/29/robots-automation-replace-jobs-mckinsey-report-800-million/> accessed 25 June 2021.

${ }^{80}{ }^{\circ}$ Number of artificial intelligence (AI) professionals by country in 2017 (in 1,000s)' (Statista) <https://www.statista.com/statistics/944319/ai-professionals-by-country/> accessed 25 June 2021.

81 ibid. 
The data below shows the increasing impact of AI on job growth, with specific reference to African realities. In terms of AI human capacity, graph 1 below shows that while South Africa (the only African country in the top 15) has approximately 15,000 AI professionals as of 2017, the United States has about 850,000 AI professionals. Curiously, as indicated in graph 2, Africa is grouped abysmally under 'Rest of the World' with regards to countries impacted by AI by 2030.

Graph 1: Number of AI professionals by country in 2017 (in thousands)

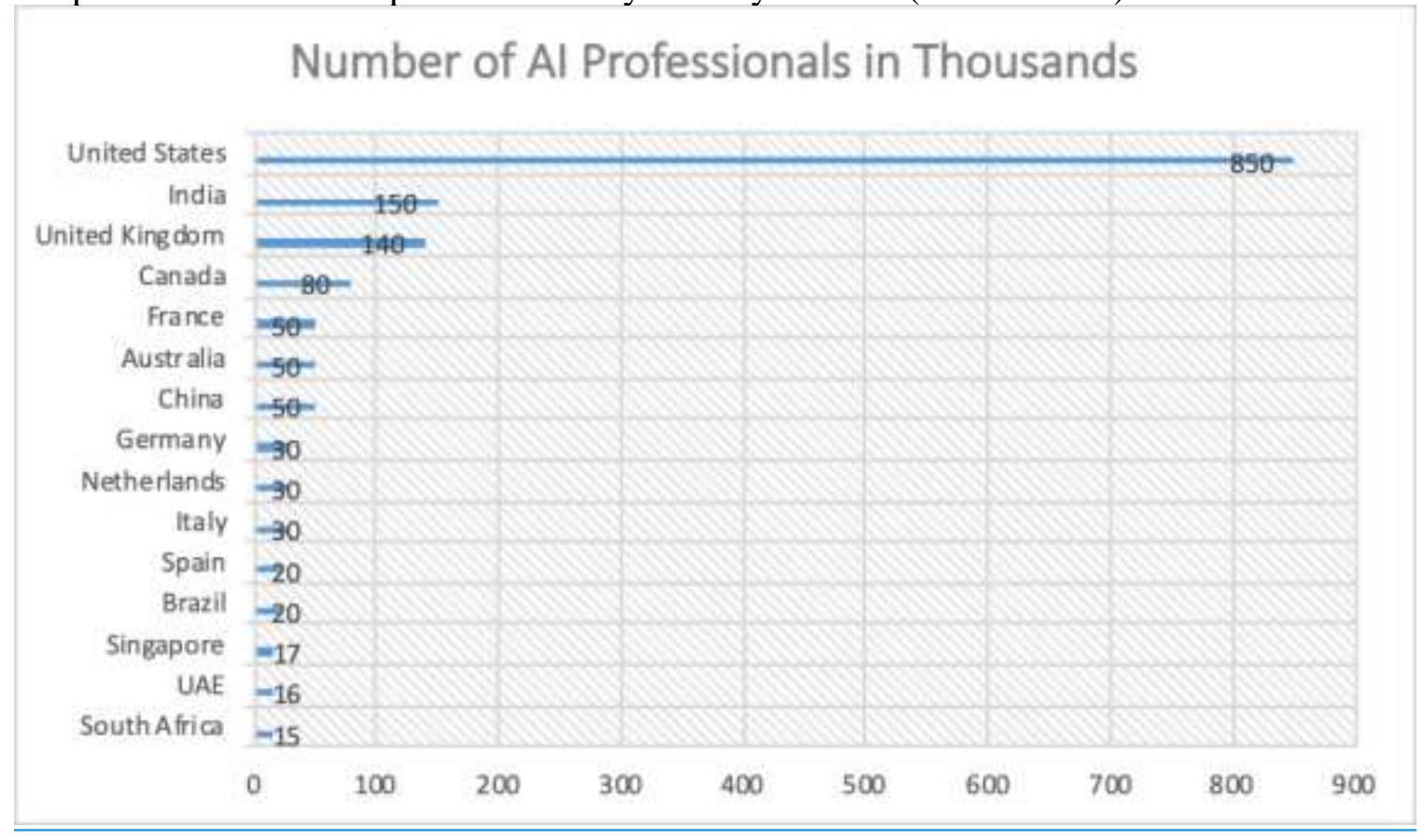

Source: Statista, Artificial Intelligence (AI)

Graph 2: Projections on the global impact of AI on GDP by 2030 


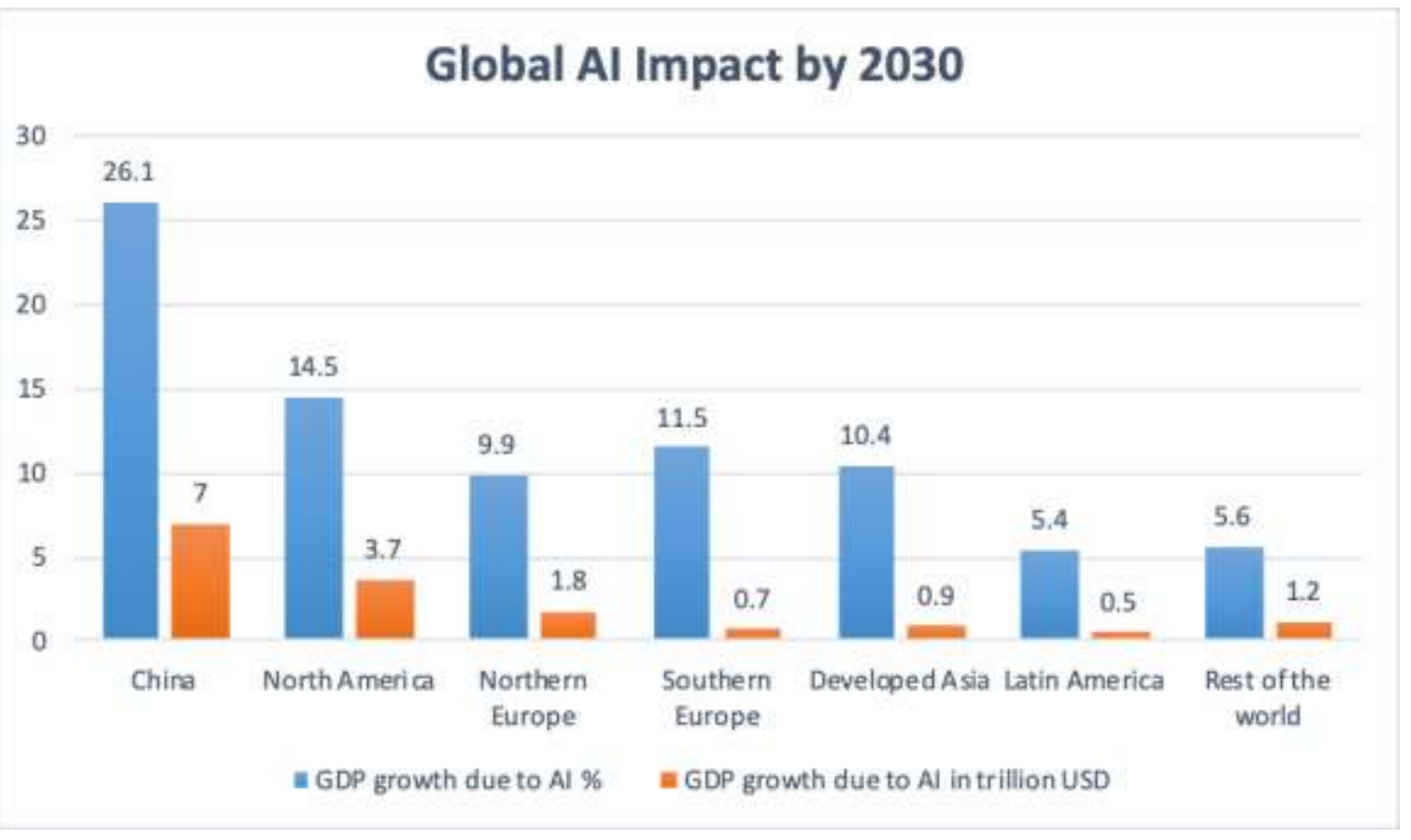

Source: Statista

\subsubsection{Right to health}

The ICESCR obligates States Parties to the Convention to take steps to ensure they fully realize the right of everyone to the enjoyment of the highest attainable standard of physical and mental health. ${ }^{82} \mathrm{AI}$ systems have been heavily deployed in the healthcare to aid diagnoses of diseases, providing more patient treatment recommendations and making health services more accessible. However, AI also has some adverse implications on the right to health. These technologies have the potential to discriminate or be programmed in a way that they prioritise factors like costs and profit over the wellbeing of the patient. ${ }^{83}$ For instance, some AI solutions are designed to recommend treatment based on the patient's insurance policy or ability to pay for the medical services, a fact which may result in denial of proper medical care due to their financial incapacitation. In addition, such AI solutions are not fully error-free. Thus, solutions like IBM's Watson have the potential to misdiagnose and recommend wrong medication. In this instance, who (or what) can be held accountable for the wrong life and death decision making?

\subsection{Prospects for a human rights-based AI deployment}

Africa has an exceptional opportunity to leverage AI technologies for transformation and effectiveness. ${ }^{84}$ These technologies have the potential to optimize solutions to the challenges facing the continent. However, the utilization of AI in Africa impacts various sectors- such as

\footnotetext{
${ }^{82}$ ICESCR art 12.

${ }^{83}$ Andersen (n 13) 14.

${ }^{84} \mathrm{Y}$ Travaly and K Muvunyi, 'The future is intelligent: Harnessing the potential of artificial intelligence in Africa' (Brookings, 13 January, 2020) <https://www.brookings.edu/blog/africa-in-focus/2020/01/13/the-future-is-intelligentharnessing-the-potential-of-artificial-intelligence-in-africa/> accessed 25 June 2021.
} 
education, health care, employment, and social life - and ultimately undermines or violates human rights. Navigating the complexities of the deployment of AI and their impacts on human rights in Africa requires a considered approach to prevent the use of AI as an instrument of social division, conquest, or violence. For example, disinformation and artificial misinformation has generated deep fakes, especially in conflict situations, ${ }^{85}$ and is used to subdue and monitor those involved in civil protests. ${ }^{86}$ China is developing facial recognition technology in Zimbabwe where individuals' facial imagery is used by monitoring and facial recognition applications. ${ }^{87}$ Weak law enforcement, nascent democratic structures, ethnic and religious divisions, and governance challenges in Africa further complicates the potential of AI to severely impact human rights. AI technologies presents a unique opportunity for African government to leverage new technology as a tool for transformative democracy. To achieve this transformation, a common governance framework for AI in Africa will create a unified approach to developing AI that integrates human rights compliance into its mode of operations.

\section{Regional Governance of Human Rights Implications of Artificial Intelligence: Lessons} for Africa

It is unclear what Africa's approach to AI is. Intra and inter-continental competition amongst African states on AI, has revealed that these technologies have the potential, to not only transform the world positively, but also violate human rights. This is due to the fact that their algorithms and other problematic mathematical tools are scalable, largely unregulated, incomprehensible and almost incontestable, thus amplifying the inherent biases and other violations on the rapidly growing African population. ${ }^{88}$ Consequently, it is important that a regional legislative instrument governing AI in Africa be enacted to limit the excesses of AI, especially with regards to human rights violations. ${ }^{89}$ We are of the considered view that African

85 R Chesney and D Citron, 'Disinformation on Steroids' (Council on Foreign Relations, 16 October 2018) <https://www.cfr.org/report/deep-fake-disinformation-steroids> accessed 22 June 2021.

${ }^{86} \mathrm{Z}$ Jones, 'Instagram apologizes for incorrectly flagging \#EndSARS posts as false information' (CBSNews, 22 October 2020) <https://www.cbsnews.com/news/nigeria-endsars-protest-apologizes/> accessed 22 June 2021.

${ }^{87}$ J Feola, 'China Exports Facial Scan Tech to Zimbabwe, Launches First "AI Technology Entry to Africa"' (Radii, 16 April 2018) <https://radiichina.com/china-exports-facial-scan-tech-to-zimbabwe-launches-first-ai-technologyentry-to-africa/> accessed 22 June 2021.

88 ibid.

${ }^{89}$ Several countries have AI-specific national initiatives. For example, Australia has its Australia's Tech Future, 2025 Digital Transformation Strategy (Vision 2025) and Ethics Framework; Austria has AIM AT 2030: Artificial Intelligence Mission Austria 2030; Belgium has its AI 4 Belgium; Canada has a set of guiding principles to ensure effective and ethical AI, Canada's Directive on Algorithmic Impact Assessment, and Canada's Directive on Automated Decision-Making; China has its Guidance on Next Generation AI Development Plan and the Three-Year Action Plan for Promoting Development of a New Generation Artificial Intelligence Industry (2018-2020); Czech Republic has the National Artificial Intelligence Strategy of Czech Republic; France has the Strategy for a Meaningful Artificial Intelligence; Germany has its AI Made in Germany; India has the National Strategy for Artificial Intelligence; Singapore has its AI Singapore and the Digital Government Blueprint; and USA has the American AI Initiative and the National Artificial Intelligence Research and Development Strategic Plan 2019 Update. 
leaders must synergize with key stakeholders in academic, private sector, and non-governmental institutions, to generate a continental blueprint that will guide the articulation of AI technologies in the continent. Existing instruments must be harmonized to facilitate sustainable development and growth on the continent. In developing proposals for reform in Africa, we examine the European Union (EU) and the Organization for Economic and Co-operation Development (OECD) framework on AI with the aim of drawing lessons for the African Union (AU). ${ }^{90}$

Hopefully, these lessons will inform the provisions of the proposed African regional framework on AI governance.

\subsection{Governance of AI in the European Union}

The EU approach to governance of AI and robotics deals with technological, ethical, legal, and socio-economic facets to create a Digital Single Market and enhance EU's research and industrial ability. ${ }^{91}$ This approach is founded on three pillars. First, it strives to be ahead of technological developments in the competitive international landscape. This arose out of EU's inability to generate private investments over a period of time. Consequently, in 2016, EU invested EUR 2.4 - 3.2 billion in AI, compared to Asia's EUR 6.5 - 9.7 billion and North America's EUR 12.1 - 18.6 billion in the same year. ${ }^{92}$ In order to compete globally, the region maximized the impact of investments at both regional and domestic levels, and encouraged synergies and cooperation across the region. To boost research and innovation, EU increased its annual investments significantly between 2018-2020. ${ }^{93}$ The investment is designed to develop platforms that will provide access to AI resources for all users in the region. Second, the goal of these platforms is to promote socio-economic objectives such as business-education partnerships aimed at attracting and retaining more AI talent within the EU; training and retraining schemes for professionals in the AI field, including those with disabilities; and supporting digital skills and competence. ${ }^{94}$ Third, in order to build trust among its citizens, the EU created an appropriate ethical and legal framework such as: General Data Protection Regulation, ${ }^{95}$ and the Ethics

\footnotetext{
${ }^{90}$ Other than the EU and OECD, other international AI initiatives include the G20 AI principles adopted during the G20 Ministerial Meeting on Trade and Digital Economy in June 2019; the Nordic-Baltic region has the Declaration on Artificial Intelligence in the Nordic-Baltic Region that was issued in 2018 and adhered to by Denmark, Estonia, Finland, the Faroe Islands, Iceland, Latvia, Lithuania, Norway, Sweden and Aland Islands; the Report of COMEST on Robotics Ethics issued by the UNESCO-World Commission on the Ethics of Scientific Knowledge and Technology in September 2017; and the Centre for AI and Robotics in Hague established by the United Nations Interregional Crime and Justice Research Institute and the Government of Netherlands in September 2017.

91 'A European Approach to Artificial Intelligence' (European Commission) <https://ec.europa.eu/digital-singlemarket/en/artificial-intelligence> accessed 22 June 2021.

92 'Communication Artificial Intelligence for Europe' (European Commission, 25 April 2018) $<$ https://ec.europa.eu/digital-single-market/en/news/communication-artificial-intelligence-europe> accessed 22 June 2021.

93 ibid.

94 ‘A New Skills Agenda for Europe' (European Commission, 10 June 2016) <https://eur-lex.europa.eu/legalcontent/EN/TXT/?uri=CELEX:52016DC0381> accessed 22 Jube 2021.
} 
Guidelines for Trustworthy AI. ${ }^{96}$ These Guidelines forms the basis for our argument on a human rights based approach to AI in Africa. The Guidelines define 'Trustworthy AI' as that which is lawful, ethical, and robust in both technical and social perspectives. ${ }^{97}$ In upholding a fundamental rights-based approach to AI, the Guidelines contain certain fundamental rights such as human dignity, rule of law, equality, and non-discrimination. Such Guidelines to be replicated in Africa, will need to include respect for human autonomy, and prevention of harm. ${ }^{98}$ Certainly,

these Guidelines require an autonomous agency or oversight to ensure its effectively. To ensure such an instrument works effectively in Africa, the AU must create a human agency and oversight body that will ensure the safety of privacy and data governance, transparency, societal and environmental wellbeing, and accountability. ${ }^{99}$ Consequently, a practical implementation of the human-centric approach to AI will be achieved. ${ }^{100}$

\subsection{Governance of $\mathrm{AI}$ in the Organization for Economic Co-operation and Development (OECD)}

The OECD has created robust, human rights based, and innovative AI principles - 2019 OECD Council Recommendation on Artificial Intelligence. ${ }^{101}$ These Principles adopt the notion that AI must be utilized sustainably, in a manner that benefits the people and planet, and is at the same time anchored on human-centred values. This will, however, require AI to be designed in a way that respects the rule of law, diversity, human rights, and democratic principles. To achieve the

${ }^{95}$ Regulates issues relating to processing of personal data, rights of the data subject, transfer of personal data to third countries or international organizations, independent supervisory authorities. See further Regulation (EU) 2016/679 of the European Parliament and of the Council of 27 April 2016 on the protection of natural persons with regard to the processing of personal data and on the free movement of such data and repealing Directive 95/46/EC (General Data Protection Regulation) <https://eur-lex.europa.eu/legalcontent/EN/TXT/PDF/?uri=OJ:L:2016:119:FULL\&from=EN>.

96 'Ethics Guidelines for Trustworthy AI' (European Commission, 8 April 2019) <https://ec.europa.eu/digital-singlemarket/en/news/ethics-guidelines-trustworthy-ai> accessed 28 June 2021.

97 ibid.

98 ibid, 12-14.

99'Improving Access to Remedy in the area of Business and Human Rights at the EU level' (EU Agency for Fundamental Rights, 10 April 2017) <https://ra.europa.eu/en/publication/2017/improving-access-remedy-areabusiness-and-human-rights-eu-level> accessed 28 June 2021; See also EU, 'Liability for Artificial Intelligence and other emerging digital technologies' (2019), Decision 2011/833/EU (OJ L 330, 14.12.2011, 39 ( Report on liability for Artificial Intelligence and other Emerging Technologies, which addresses specific challenges to existing tort law regimes posed by emerging digital technologies such as damage, causation, wrongfulness and fault, vicarious liability, and strict liability).

100 Other cooperative instruments designed to address issues resulting from AI usage include EU Declaration on Cooperation on Artificial Intelligence, Coordinated Plan on Artificial Intelligence (COM (2018) 795 final). See further European Commission, 'EU Member States sign up to cooperate on Artificial Intelligence' <https://ec.europa.eu/digital-single-market/en/news/eu-member-states-sign-cooperate-artificial-intelligence> accessed 28 June 2021; European Commission, 'Coordinated Plan on Artificial Intelligence (COM (2018) 795 final) <https://knowledge4policy.ec.europa.eu/publication/coordinated-plan-artificial-intelligence-com2018-795final_en> accessed 28 June 2021.

101 ‘OECD Principles on AI’ (OECD) <https://www.oecd.org/going-digital/ai/principles/> accessed 28 June 2021. 
foregoing, it is important that the principles accomplish the resultant benefit of transparency whereby citizens can comprehend and challenge AI outcomes. ${ }^{102}$

The Recommendation also advised its adherents to implement several suggestions, in tandem with the above principles, in their domestic policies and international co-operation, channelling special focus on Small and Medium Sized firms. Though voluntary, the rationale for developing

the Recommendation was that AI has the potential of improving the general well-being of the people, enhance productivity, and effectively react to global challenges such as climate change. ${ }^{103}$ However, beneath the underlying benefits are the implications AI-enabled solutions have on the society and economies, notably concerning human rights and democracy, economic changes and inequalities, and impacts on the labour market. ${ }^{104}$ This is significantly important for an African discourse and argument in this paper to create regulations on AI. The need for a balance necessitates a stable policy environment, especially at the regional level, to cultivate trust and embrace AI in the society with the underlying aim of promoting a human-centred approach to the development of AI. To create the balance, the utilization of AI within the African continent should consider the need for AI systems being human centred. Accordingly, the solutions should be designed in a way that they respect the rule of law, democratic principles, and human rights. Equally, the solutions should be transparent, coupled with responsible disclosure in a bid to ensure people can comprehend and challenge AI-based outcomes. Additionally, the entities deploying, or operating AI systems must be accountable to the society for their proper functioning. These are the fundamental principles upon which governance of AI under the OECD is anchored. What lessons can Africa learn from the OECD experience? The next section discusses these approaches and implications of an AI architecture in Africa.

\subsection{Governance of AI in Africa}

The governance of AI in Europe is anchored on fundamental rights and liberties. Both the EU and OECD emphasizes the need to promote trust and embrace AI in an ethical manner with the aim of promoting the rights of individuals. This is instructive for Africa.

In Africa, the internet or social media platforms could be used as tools of mass surveillance and infringement on the right to privacy in the digital environment. ${ }^{105}$ Thus, the Declaration on Internet Governance and Development of Africa's Digital Economy (the Declaration), recognizes that the internet is a dynamic force for economic, social, and cultural development. ${ }^{106}$ Yet, it does not encourage, facilitate, or promote the respect of fundamental values and rights of individuals. Furthermore, the Declaration recommends the guarantee of an effective legal and

\footnotetext{
${ }^{102}$ 'Recommendation of the Council on Artificial Intelligence' (OECD Legal Instruments, <https://legalinstruments.oecd.org/en/instruments/OECD-LEGAL-0449> accessed 28 June 2021.

2019) 
regulatory environments suitable for the growth of Africa's digital economy through innovative applications and services. ${ }^{107}$ Although this Declaration broadly covers the internet, much like the EU approach, the provisions under the Declaration are instructive for promoting rights-based approach to AI in Africa. Therefore, considering its voluntary nature, and given the massive infringement of the people's rights in the field of internet and AI, it is imperative that a regulatory framework be put in place in Africa to protect peoples' data, both online and offline -

this is a significant lesson from the EU approach.

The AU Convention on Cyber Security and Personal Data Protection governs three major components: electronic transactions; personal data protection; and promoting cyber security and combating cybercrime. ${ }^{108}$ However, AI protection goes beyond infringement of personal data. For example, AI poses other societal problems such as trust and confidence in AI-enabled solutions among citizens, adequate and effective grievance mechanisms. This necessitates the urgent need for a comprehensive African AI-specific legal and regulatory framework that is human rights based. However, unlike the EU, Africa suffers from weak enforcement capabilities and corruption. This creates a challenge for enforcement of AI- centric solutions anchored on fundamental rights and liberties. The UNGPs on Business and Human Rights obliges states to enforce laws that are aimed at requiring business enterprises to respect human rights. Failure to enforce such laws, which include privacy and anti-bribery laws, is deemed a substantial legal gap in state practice. ${ }^{109}$ Thus, the need for a coherent AI-specific African framework that will govern AI systems and solutions. ${ }^{110}$

\subsubsection{Usage and Deployment of AI in Africa}

It is important to note that the challenges AI pose to human rights are discussed in the context of state and private actors. The AU Framework should institute very high standards on the deployment of AI and algorithmic decision-making systems within the public and private sector. These standards must be designed around mandatory human rights impact assessment and have an open, transparent, and competitive procurement standard. ${ }^{111}$ The mandatory human rights impact assessment will identify human rights risks prior to acquisition and through its life cycle.

Such assessment should include audits by independent experts; measures to mitigate existing and

107 ibid Principle 14.

108 African Union Convention on Cyber Security and Personal Data Protection (adopted 27 June 2014) (AUCCSPDP).

${ }^{109}$ UNCHR, 'Guiding Principles on Business and Human Rights: Implementing the United Nations 'Protect, Respect and Remedy' Framework' (21 March 2011) UN Doc A/HRC/17/31

$110 \mathrm{O}$ Abe and A Ordor, 'Local content requirements and social inclusion in global energy markets: Towards a business and human rights content' in D Olawuyi (ed), Local Content and Sustainable Development in Global Energy Markets (CUP 2021) 392.

111 See 'Kenya's opposition coalition alleges French OT-Morpho tampered with election results; co. denies allegations', (Business and Human Rights Resource Centre) <https://www.business-humanrights.org/en/latestnews/kenyas-opposition-coalition-alleges-french-ot-morpho-tampered-with-election-results-co-denies-allegations/> accessed 28 June 2021. 
potential risks; plan to terminate usage or acquisition if it is discovered that there is the probability of extremely adverse implications on human rights.

The AU Framework should also ensure that transparency of an AI system's purpose and usage does not unnecessarily infringe on the developer's intellectual property rights. To achieve this, there must be the requirement for regular reports by the government on where and how they use AI and allowing independent audits of systems. The Framework must also avoid 'black box systems' that is, using AI systems only when they can comprehend how they work. The essence of this Framework is to have accountability mechanisms in place safeguarding the sustainable utilization of AI.

Private companies that provide AI solutions have a responsibility to respect human rights and should always take appropriate measures at meeting this goal. The AU Framework must mandate corporate entities to conduct due diligence on the human rights implications of acquisition, usage, or deployment of AI systems including identifying both direct and indirect harm; conduct relevant stakeholder consultations; human rights impact assessment by both the private and public sector if the AI system is to be used by a public entity. Corporate actors have to adopt measures that prevent, mitigate or prohibit AI adverse impacts. Such measures will generally include complying with diversity and inclusion of expertise rules to avoid input bias by design and conduct continuous assessments on the AI systems to identify and mitigate existing and potential threats to human rights.

Considering the egregious nature of corporate conduct in Africa, additional mandatory internal accountability mechanisms for the functioning of AI systems must be required of MNCs. These mechanisms will guarantee that companies are held accountable for the development of AI systems; establish clear and realistic processes by which aggrieved persons can submit their complaints and seek timely redress for any corporate induced human rights violations, delineate responsibility and accountability between the AI vendor and client, and establish the vendor's duty to inform the client of the potential human rights risks of an AI system and train the client on how to mitigate such risks.

\subsubsection{Access to effective remedies}

An effective approach in establishing a framework for the regulation of AI must consider how technology supports access to remedies, such as increasing workers voice, reducing income inequality, and improving communication and information. While these technologies offer numerous value-added outcomes for businesses, such as information on workers and customers experiences, the basis for adapting should be to provide action-oriented information to accelerate access to remedy for victims of human rights violations. The fundamental question is who provides the remedy when a machine-created algorithm discriminates against people, restrict freedom of expression, or when automation leads to mass displacement of labor. ${ }^{112}$ The Framework must contain provisions mandating African states to have within their territories effective domestic judicial mechanisms that can adjudicate on exploitations arising from the use of AI. ${ }^{113}$ Such mechanisms must extend beyond reduction of legal, practical and other relevant

\footnotetext{
${ }^{112}$ A Norton, Automation and Inequality. The changing world of work in the Global South (IIED August 2017)
} 
barriers that could impede access to remedy. Businesses must design operational-level grievance mechanism for their workers to ensure that victims have recourse to remedy resulting from decisions made by machines and algorithms, not humans. These mechanisms must be effective and easily accessible upon complaint by an aggrieved party, while also guaranteeing enforcement of Regulations and company policies. ${ }^{114}$

\section{Conclusion}

Human rights compliance is fundamental to positive utilization of AI technologies in regions such as Africa. In situations where deployment of AI results in negative consequences, a regional framework anchored on human rights systems will curtail the excessive tendencies of state to maliciously operationalize AI. Thus, African states must strengthen their core duty to protect human rights by collaborating with academic institutions in providing human centred AI solutions. A human rights approach to AI must be integrated in school curriculum, business models, and product designs. Where the risk of negative human rights impact is greater than the positives of the AI solution, such solution must be disabled or prevented from being fully operational by the state. Providers of AI technologies must be able to conduct human rights impact assessment and corporate due diligence on their solutions to ensure that human rights concerns are addressed and mitigated.

Certainly, AI has facilitated African's access to education, health, public service, finance, transportation amongst others. That notwithstanding, AI has (and continues to) infringe on citizens' rights to freedoms of expression, movement, equality, non-discrimination, health, work, adequate standard of living, and democratic values. A protective mechanism to curtail the excessive disruption of AI, with particular reference to human rights implications is essential in Africa. Furthermore, a governance architecture for AI in Africa will generate a uniform and shared value approach to developing AI that considers the importance of fundamental rights and liberties in its operational framework. Such mechanisms guarantee trust and confidence in the AI systems. A legal instrument at the AU level which identifies opportunities and unpack solutions on how to mitigate the dangers of $\mathrm{AI}$ is pertinent to the sustainable utilization of these technologies in the continent. This will safeguard African citizens' access to better healthcare, education, and transportation. It will also further protect the integrity of the internet, prevent belligerent action by non-state actors, and the wanton disregard of citizens lives and right to participate in peaceful protest, amongst other rights and liberties.

\footnotetext{
${ }^{113}$ DIGDADE (n 105) Principle 26.

114 ibid Principle 30.
} 